\title{
Drug companies divided
}

\section{Washington}

Proposals introduced in the US Congress last week may dilute the benefits to drug companies of the Orphan Drug Act by forcing them in some cases to "share" the temporary marketing monopoly that the Act permits. Representative Henry Waxman (Democrat, California), chairman of a health and environment subcommittee, has introduced two bills to 'fine tune' the Act, which at present provides drug companies with grants, tax credits and a seven-year-period of marketing exclusivity in the United States as incentives to develop drugs for diseases that affect fewer than 200,000 people.

Since its inception in 1983, 333 drugs have been issued with orphan drug status, and 45 have been approved by the US Food and Drug Administration (FDA). But congressional concern over the high prices of some profitable drugs protected from competition by the Act has prompted Waxman to take action. He believes that "in a small number of cases, the Act has provided monopoly protection for drugs that are very profitable and that would have been developed without the incentives of the Act".

Three drugs - human growth hormone, aerosol pentamidine (approved to treat an AIDS-related pneumonia) and erythropoietin (EPO, approved to treat anaemia in patients with chronic renal failure) - cause particular concern. Hearings were held in February to consider whether orphan status for these drugs had resulted in unwarranted monopolies and unnecessarily high prices.

Perhaps the most controversial aspect of Waxman's first bill is a provision that would allow more than one company to share marketing exclusivity if simultaneous development could be demonstrated. Abbey Meyers, executive director of the National Organization for Rare Disorders (NORD), originally opposed any form of 'shared exclusivity' but now supports the bill. She regrets the need for changes but recognizes that "many in Congress are very disturbed by what they perceive as abuses of the act". Genetics Institute, whose version of EPO is blocked by the orphan drug status of Amgen's EPO product (see Nature 344, $800 ; 1990)$, left the Industrial Biotechnology Association (IBA) in March after the trade group voted against changes to the Orphan Drug Act. Gabriel Schmergel, president and chief executive officer of Genetics Institute, praises Waxman's initiative as a "creative way of fine tuning [the act] and still retaining the incentives for the true orphans".

According to Schmergel, EPO, the biggest drug to come out of biotechnology, has worldwide sales estimated at about $\$ 450$ million for 1990 . "In the second year of its history, EPO is going to outsell, by a factor of maybe two, tissue plasminogen activator, and its most important indications are not yet approved", says Schmergel. "Commonsense tells you it's not an orphan." But Amgen's Mark Brand argues that, without the protection of orphan drug status, "we wonder whether or not there will be sufficient private-sector investment".

The proposed amendments would also require the FDA to assess future population growth before making orphan drug designations, which could have important implications for AIDS drugs. Moreover, drugs would lose their exclusivity if the treatment population exceeded the 200,000 limit. The second bill would extend the tax-credit programme to include human clinical trials and animal testing.

The issue has divided not only the biotechnology and pharmaceutical industries but also the trade associations.

Pamela Bridgen, executive director of the Association of Biotechnology Companies, sees Waxman's proposals as a "positive step". Both the IBA and the Pharmaceutical Manufacturers Association, however, oppose changes that would undermine what they believe to be the Act's key incentive - market exclusivity. There is likely to be heavy lobbying in government circles as both sides rally for support. As Schmergel says, "it's going to be a fight.

Diane Gershon

\section{Postal tests on the way}

\section{Washington}

ENCOURAGED by the success of the drug AZT in treating people infected by the HIV-1 virus but showing no symptoms of AIDS, the US Food and Drug Administration (FDA) has lifted its opposition to AIDS testing outside clinics and hospitals, a decision that could lead to the marketing of home test kits for HIV-1 infection in the United States. Home testing had previously been ruled out because counselling and treatment for those testing positive could not be guaranteed.

FDA officials have accepted an application from University Hospital Laboratories Corporation (UHLC) for a licence to market a home blood-collection kit, which would allow users to mail blood samples to a testing laboratory and telephone for the results. On receipt of test results, expert counselling would be provided by telephone.

To avoid mailing potentially hazardous liquid blood samples, buyers of the UHLC kit would impregnate a small piece of filter paper with blood from a pin-pricked finger. The company's clinical trials show that the method is as reliable as tests done on liquid samples drawn by syringe. UHLC would then perform the standard HIV-1 antibody test, with the follow-up Western blot test recommended by the FDA to exclude false positives.

Two years ago, the FDA refused to review similar applications because of fears about the reliability of home test kits and the effectiveness of telephone counselling. But in an abrupt policy shift, the FDA recently wrote to more than 20 biotechnology companies saying it would now be prepared to look at applications.

UHLC's demonstration that an HIV-1 antibody test can work satisfactorily on blood samples collected at home was a factor in the change of policy, according to
Paul Parkman, director of the FDA's centre for biologics. But a more important consideration was that AZT has recently been shown to be effective in treating asymptomatic carriers of HIV-1 as well as patients with full-blown AIDS. Parkman says that the FDA has softened its stance on home testing because anybody testing positive can usefully be treated with AZT, a benefit that federal officials believe outweighs the risk associated with telephone counselling.

But AIDS organizations oppose the FDA's policy shift. They still consider face-to-face counselling and the availability of back-up clinical support to be essential components of any test protocol. Jean McGuire, executive director of the US AIDS Action Council, describes the FDA's move as "worrisome". The biggest challenge posed by home testing is not the threat of inaccurate results or a breach of confidentiality but the problem of counselling, she says.

Robert Thewes of the National Association of People with AIDS doubts whether the home testing scheme could work without endangering the anonymity of its users, a problem heightened, he says, by the fact that anyone testing positive for HIV-1 in the United States runs the risk of losing health care insurance and possibly his or her job.

Nevertheless, UHCL spokesman Elliot Millenson believes that more Americans would willingly be tested for HIV-1 infection if they could do so in the privacy of their own homes, and that the advantages of home test kits for gathering epidemiological data would be considerable. In a survey conducted by UHLC, about 60 per cent of respondents said they would prefer a home test to a conventional test in a doctor's surgery or a clinic.

David Concar 